\title{
Active lifestyle enhances protein expression profile in subjects with Lewy body pathology
}

\author{
Caroline Cristiano Real ${ }^{1,2}$, Cláudia Kimie Suemoto ${ }^{3}{ }^{\oplus}$, Karina Henrique Binda ${ }^{2 \oplus}$, Lea Tenenholz Grinberg ${ }^{4,5}$, \\ Carlos Augusto Pasqualucci ${ }^{\circledR}{ }^{\oplus}$, Wilson Jacob-Filho ${ }^{\circ}$, Renata Eloah de Lucena Ferretti-Rebustini ${ }^{\circ}{ }^{\odot}$, \\ Ricardo Nitrini ${ }^{\top}$, Renata Elaine Paraizo Leite ${ }^{3 \odot}$, Luiz Roberto de Britto ${ }^{2 \odot}$
}

\begin{abstract}
Clinical trials of the effects of physical activity have reported improvements in symptoms and quality of life in patients with Parkinson's disease (PD). Additionally, morphological brain changes after exercising were reported in PD animal models. However, these lifestyle-related changes were not evaluated in postmortem brain tissue. Objective: We aimed to evaluate, by immunohistochemistry, astrocytes, tyrosine hydroxylase (TH) and structural proteins expression (neurofilaments and microtubules MAP2) changes in postmortem brain samples of individuals with Lewy body pathology. Methods: Braak PD stage $\geq 11$ samples, classified by neuropathology analysis, from The Biobank for Aging Studies were classified into active $(n=12)$ and non-active $(n=12)$ groups, according to physical activity lifestyle, and paired by age, sex and Braak staging. Substantia nigra and basal ganglia were evaluated. Results: Groups were not different in terms of age or gender and had similar PD neuropathological burden ( $p=1.00)$. We observed higher $\mathrm{TH}$ expression in the active group in the substantia nigra and the basal ganglia $(p=0.04)$. Astrocytes was greater in the non-active subjects in the midbrain $(p=0.03)$ and basal ganglia $(p=0.0004)$. MAP2 levels were higher for non-active participants in the basal ganglia $(p=0.003)$ and similar between groups in the substantia nigra $(p=0.46)$. Neurofilament levels for non-active participants were higher in the substantia nigra $(p=0.006)$ but not in the basal ganglia $(p=0.24)$. Conclusion: Active lifestyle seems to promote positive effects on brain by maintaining dopamine synthesis and structural protein expression in the nigrostriatal system and decrease astrogliosis in subjects with the same PD neuropathology burden.
\end{abstract}

Keywords: Life style, aging, Lewy bodies, postmortem examination, Parkinson disease, dopamine, astrocytes.

\section{O ESTILO DE VIDA ATIVO MELHORA O PERFIL DE EXPRESSÃO DE PROTEÍNAS EM INDIVÍDUOS COM A PATOLOGIA DE CORPOS DE LEWY}

RESUMO. Estudos dos efeitos da atividade física relataram melhora nos sintomas e na qualidade de vida de pacientes com doença de Parkinson (DP). Além disso, alterações morfológicas do cérebro após o exercício físico foram relatadas em modelos animais da DP. No entanto, essas mudanças relacionadas ao estilo de vida não foram avaliadas em tecido cerebral post-mortem. Objetivo: Avaliar a expressão de astrócitos, tirosina hidroxilase $(\mathrm{TH})$ e a expressão de proteínas estruturais (neurofilamentos e microtúbulos MAP2) por imuno-histoquímica, em amostras cerebrais post-mortem de indivíduos com corpos de Lewy. Métodos: Amostras com estágio de Braak para DP $\geq 1 \|$, classificação neuropatológica, fornecidas pelo biobanco de estudos do envelhecimento foram classificadas em grupos ativos ( $n=12$ ) e não ativos ( $n=12)$, de acordo com o estilo de vida (atividade física), e pareados por idade, sexo e estadiamento de Braak. Analisou-se a substância negra e gânglios da base. Resultados: Idade, sexo e classificação para DP foram semelhantes $(p=1,00)$. Observou-se maior expressão de TH no grupo ativo $(p=0,04)$. Amostras de não ativos revelaram maior expressão de astrócitos no mesencéfalo $(p=0,03)$ e nos gânglios da base ( $p=0,0004)$; MAP2 nos gânglios da base $(p=0,003)$; os níveis de neurofilamentos foram maiores na substância negra $(p=0,006)$. Conclusão: 0 estilo de vida ativo parece promover efeitos positivos no cérebro, mantendo a síntese de dopamina e a expressão estrutural de proteínas no sistema nigrostriatal e com diminuição da ativação de astrócitos em indivíduos com a mesma classificação neuropatológica para a DP.

Palavras-chave: estilo de vida, envelhecimento, corpos de Lewy, autópsia, doença de Parkinson, dopamina, astrócitos.

This study was conducted at the Laboratory of Cellular Neurobiology, Department of Physiology and Biophysics, Instituto de Ciencias Biomedicas, Universidade de São Paulo, São Paulo, SP, Brazil. Brain tissue was obtained from the Brain Bank of the Brazilian Aging Brain Study Group, Faculdade de Medicina, Universidade de São Paulo, São Paulo, SP, Brazil.

1'Laboratoy of Nuclear Medicine, Faculdade de Medicina, Universidade de São Paulo - São Paulo, SP, Brazil. 2Laboratory of Cellular Neurobiology, Department of Physiology and Biophysics, Instituto de Ciencias Biomedicas, Universidade de São Paulo - São Paulo, SP, Brazil. ${ }^{3}$ Division of Geriatrics, Faculdade de Medicina, Universidade de São Paulo - São Paulo, SP, Brazil. " Memory and Aging Center, University of California San Francisco - San Francisco, California, United States of America. ${ }^{5}$ Department of Pathology, Faculdade de Medicina, Universidade de São Paulo - São Paulo, SP, Brazil. ${ }^{6}$ Medical-Surgical Nursing Department, Escola de Enfermagem, Universidade de São Paulo - São Paulo, SP, Brazil. 'Department of Neurology, Faculdade de Medicina, Universidade de São Paulo - São Paulo, SP, Brazil.

Caroline Cristiano Real. Rua Doutor Ovídio Pires de Campos, 872 - Cerqueira César - 05403-911 São Paulo SP - Brazil. E-mail. caroline.c.real@gmail.com Disclosure: The authors report no conflicts of interest.

Funding: This study was supported by The São Paulo Research Foundation (FAPESP, Brazil - \#13/25049-2 and \#12/50329-6). CCR - Post-doctoral fellowship from The São Paulo Research Foundation (FAPESP), Brazil - Grant number: 2013/25049-2. KHB - Scientific Initiation Scholarship from The São Paulo Research Foundation (FAPESP), Brazil - Grant number: 2016/16166-3. LTG - supported by National Institutes of Health (NIH), USA - Grant number: K24AG053435. LRB - supported by The São Paulo Research Foundation (FAPESP) and National Council for Scientific and Technological Development (CNPq), Brazil.

Received on August 10, 2020. Accepted in final form on November 03, 2020 


\section{INTRODUCTION}

lthough Parkinson disease (PD) is the most com$\mathrm{I}_{\text {mon form of } \alpha \text {-synucleinophaties with movement }}$ disorder, and second most common neurodegenerative disorder worldwide, doubts about PD are still unclear. ${ }^{1} \mathrm{PD}$ neuropathology classification is based on the detection of altered $\alpha$-synuclein, responsible for the formation of Lewy bodies in the tissue and neuroanatomic distribution of this alteration in the brain, as proposed by the Braak staging criteria for $\mathrm{PD},{ }^{2}$ classifying it as a Lewy body pathology (LBP). ${ }^{1}$ Several studies have shown a variety of possible mechanisms for $\mathrm{PD}$, including increased oxygen free radicals, mitochondrial dysfunction, protein degradation and aggregation dysfunction, and neuroinflammation, ${ }^{3}$ which is responsible for promoting the death of dopaminergic cells. The levels of tyrosine hydroxylase (TH) are severely reduced in the substantia nigra (SN) of PD patients. ${ }^{4} \mathrm{TH}$ is decreased after dopaminergic cell death, thus it is considered a good index of dopaminergic function in postmortem studies. ${ }^{4}$

$\mathrm{PD}$ is increasingly thought to be associated with glial pathology. Astrocytes, the most present class of glial cells in the mammalian central nervous system (CNS), has been highlighted as key molecule of neuroinflammation and has a very heterogeneous functional level. ${ }^{5} \mathrm{Gli}$ al fibrillary acidic protein (GFAP) is a protein expressed in astrocytes widely described for having a relationship with neurodegenerative disease progression and CNS injuries, ${ }^{6}$ as well as dysregulation of nervous system homeostasis. ${ }^{7}$ Recently, research on neurodegenerative disorders has focused on understanding the role of astrogliosis in the disease pathophysiology, and has also been seem as a promising cellular source not only to study CNS pathologies initiation and progression, but also as a therapeutic target. ${ }^{8}$

In addition, structural proteins, such as microtubules and neurofilaments, are also important to be evaluated due to their importance for neuronal integrity and function. Previous studies revealed that, in neurons, microtubules maintain the integrity of axons by forming stable bundles and facilitate the transport of synaptic vesicles. One of the mechanisms used by cells to regulate the stability and dynamics of microtubules involves the interaction of microtubules with microtubule-associated proteins (MAP), including microtubule-associated protein-2 (MAP2). Interaction between MAP have either stabilizing or destabilizing effects on the microtubules. ${ }^{9}$ MAP2 is the major neuronal component, providing structural support for the axon and regulating its diameter, therefore, dysfunction in their synthesis can directly affect neurotransmission..$^{9}$ Abnormal patterns of MAP2 in PD brain tissue have also been observed, and can be responsible for the destabilization of microtubule structures. ${ }^{10}$ In neurodegenerative diseases, including PD, microtubules destabilization may be a vital step in the pathogenesis. ${ }^{11}$

Neurofilaments, whose subunits have different domain structures and function, are the only neuron-specific intermediate filaments. ${ }^{12}$ They are important to give shape to cells; to determine axonal caliber, which controls signal conduction; to regulate the transport of synaptic vesicles; and to modulate synaptic plasticity. ${ }^{13}$ On the other hand, the accumulation of neurofilament proteins can develop aggregates, being one of the responsible for the formation of Lewy bodies in PD. ${ }^{13}$

Several studies have investigated interventions aimed to improve the quality of life of PD patients. Physical activity in older people is important to prevent the disease,${ }^{14}$ as was seen in a recent longitudinal study with self-reported physical activity that revealed a decline in the clinical progression of PD. ${ }^{15}$ In PD animal models, we have previously shown that exercise protocols promoted a reduction in inflammatory markers, ${ }^{16}$ and an increase in dopamine function. ${ }^{17}$ Despite the symptomatic improvements found in clinical trials, studies of human postmortem brains correlating physical activity with morphological changes are lacking.

Therefore, we aimed to evaluate, in a human postmortem brain tissue with proven Lewy body pathology classified as PD by Braak criteria, the association between active or non-active lifestyle and structural proteins (MAP2 and neurofilaments) and astrogliosis, evaluated by GFAP. The dopaminergic system function was also investigated by measuring the $\mathrm{TH}$ protein expression in these individuals.

\section{METHODS}

\section{Participants}

From 2004 to 2016, the Brain Bank from the Biobank for Aging Studies (BB-BAS) included 1,123 participants. The inclusion criteria is to be 50 years old or older. Exclusion criteria included acute brain lesions (e.g., infarctions, hemorrhages, cancer, or trauma); severe chronic conditions that could interfere in brain homeostasis (e.g., severe heart failure and dialytic chronic kidney failure); subjects without a reliable next-of-kin to answer the clinical interview; and subjects with acidosis due to severe agonal status (cerebrospinal fluid $\mathrm{pH}<6.5) .{ }^{18}$ For this study, all participants with a neuropathological diagnosis of LBP classified as Braak PD stage $\geq$ III were included. Participants with incomplete information about lifestyle and bedridden were excluded. The deceased's 
next-of-kin signed an informed consent to donate the brain. All procedures were approved by local and national human research ethics committees (Certificate number 285/04, and 1181 CEPSH/ICB/USP).

\section{Postmortem clinical evaluation}

Clinical assessment was obtained through a clinical interview with the next-of-kin. The protocol included semi-structured questionnaires that assessed clinical-functional and neuropsychiatric abilities, which were validated for postmortem interviews. ${ }^{19}$ The interview included the Tanner questionnaire, a brief, sensitive and specific screening questionnaire for parkinsonism, and the Clinical Dementia Rating (CDR) scale for cognitive evaluation. The Tanner questionnaire contains nine questions about parkinsonism symptoms (one point for each symptom). The CDR evaluates the presence and severity of cognitive impairment by assessing six domains: memory, orientation, judgment and problem solving, community affairs, home and hobbies, and personal care.

Because of the nature of this postmortem study, only the informant section of the CDR was used. Participants were then classified into five categories: normal cognition $(C D R=0)$; questionable dementia $(C D R=0.5)$; mild dementia $(C D R=1)$; moderate dementia $(C D R=2)$; and severe dementia $(C D R=3)$. Subjects with $C D R>0$ were characterized with cognitive impairment. Participants were considered to have an active lifestyle if the nextof-kin reported that the subject had a walking routine of at least three times a week in the last 12 months before death, and was active in household activities. The non-active individuals were paired with active ones based on age, gender, and PD Braak staging. ${ }^{18}$ These information were obtained from the BB-BAS database.

\section{Neuropathological evaluations}

Brain tissue was obtained within 24 hours after death. One hemisphere was fixed in $4 \%$ buffered paraformaldehyde and specific areas were embedded in paraffin: middle frontal gyrus, middle and superior temporal gyri, angular gyrus, superior frontal, anterior cingulate gyrus, visual cortex, hippocampal formation at the level of the lateral geniculate body, amygdala, basal ganglia at the level of the anterior commissure, thalamus, midbrain, pons, medulla oblongata, and cerebellum. Blocks were sectioned into $5-\mu \mathrm{m}$-thick sections stained with hematoxylin and eosin. Immunohistochemistry was performed with antibodies against $\beta$-amyloid (4G8, 1:10,000; Signet Pathology Systems, Dedham, Massachusetts), phosphorylated tau (PHF-1, 1:2,000; gift from Peter Davies, New York), TDP-43 (1:500,
Proteintech, Chicago, Illinois), and $\alpha$-synuclein (EQV1, 1:10,000; gift from Kenji Ueda, Tokyo, Japan). ${ }^{20}$ Internationally accepted neuropathological criteria were used to stage and diagnose the brain pathologies. ${ }^{21-25}$ We considered the diagnosis of Lewy body disease or PD when Braak PD stage $\geq 3 .{ }^{25}$

The neuropathological classification was performed on all brains donated to BB-BAS. Based on the neuropathological classification, 100 participants were diagnosed with PD. Among these participants, 12 subjects were classified as active, and 34 were non-active. From the non-active group, 12 cases were selected and paired by age and gender with the active group. Therefore, this study included 24 subjects divided between active $(\mathrm{n}=12)$ and non-active groups $(\mathrm{n}=12)$ (Figure 1$)$. The two groups had similar Braak PD staging $(\mathrm{p}=1.00)$. In addition, some participants also had Alzheimer disease (AD) neuropathology, but Braak staging for $\mathrm{AD}$ was similar between groups $(\mathrm{p}=1.00)$.

Selected samples were submitted to immunohistochemistry to evaluate structural proteins (neurofilaments and MAP2), astrogliosis (GFAP), and dopaminergic system $(\mathrm{TH})$ in the midbrain (including the $\mathrm{SN}$ ) and the basal ganglia (Caudate and Putamen nuclei). For that, slides with brain tissue were submitted to antigenic-retrieval treatment by immersion in citrate buffer pH 6.0 in a steamer at $95^{\circ} \mathrm{C}$ for $45 \mathrm{~min} .{ }^{26}$ The sections were incubated overnight at $4^{\circ} \mathrm{C}$ with primary antibodies, namely: TH (Millipore, MAB5280, 1:2,000), neurofilaments (Zymed, 18-0171, 1:2,000); MAP2 (Millipore, MAB3418, 1:2,000) and GFAP (Sigma, G3893, 1:2,000). After secondary antibody incubation (Jackson ImmunoResearch Laboratories, 715-065-151, 1:200), the sections were incubated for $1 \mathrm{~h}$ at $37^{\circ} \mathrm{C}$ with avidin-biotin-peroxidase complex (Vectastain ${ }^{\circledast} \mathrm{ABC}$ Kit; Vector Laboratories, 1:100), and the slices were incubated with $0.05 \% 3,3$ '-diaminobenzidine tetrahydrochloride and a $0.01 \%$ solution of hydrogen peroxide in phosphate buffer. Intensification of the reaction was performed using $0.05 \%$ osmium tetroxide in water. The sections were dehydrated, cleared with xylol, and coverslipped with Permount (Fisher).

Five selected digital images with 10x magnification were acquired using a Nikon E1000 microscope (Melville, NY, USA) and a Nikon DMX1200 digital camera (Nikon Imaging Software ACT-U). An independent researcher blinded to the subject's physical activity status analyzed the integrated optical density of immunolabeling in five areas of $0.58 \mathrm{~mm}^{2}$ from each digital image, totaling an analysis area of $3 \mathrm{~mm}^{2}$ for each sample. Digital images were analyzed using the ImageJ software, version $1.52 \mathrm{a}$ (NIH, USA). For image analysis, the digital 
image was opened, a square of $0.58 \mathrm{~mm}^{2}$ was drawn, and the analysis instrument was used (Set Measurements Integrated Density - Measure).

\section{Statistical analysis}

Data are represented as mean and standard deviations for continuous variables and frequencies for categorical variables. As the active and non-active groups were paired, we used paired $t$-tests to compare protein expression between groups. The McNemar test was used to compare categorical variables. $\mathrm{P}<0.05$ was adopted.

\section{RESULTS}

Table 1 describes the characteristics of the samples. Tanner scores showed fewer parkinsonism symptoms among active participants compared to non-active ones $(p=0.03)$. The non-active group revealed four subjects classified as CDR 0 , three classified as CDR 0.5 , one as CDR 1, two subjects as CDR 2, and two subjects as CDR 3 . For the active group, there were seven subjects classified as CDR 0 , one classified as CDR 1 , one subject as CDR 2, and three as CDR 3 $(\mathrm{p}=0.45)$.

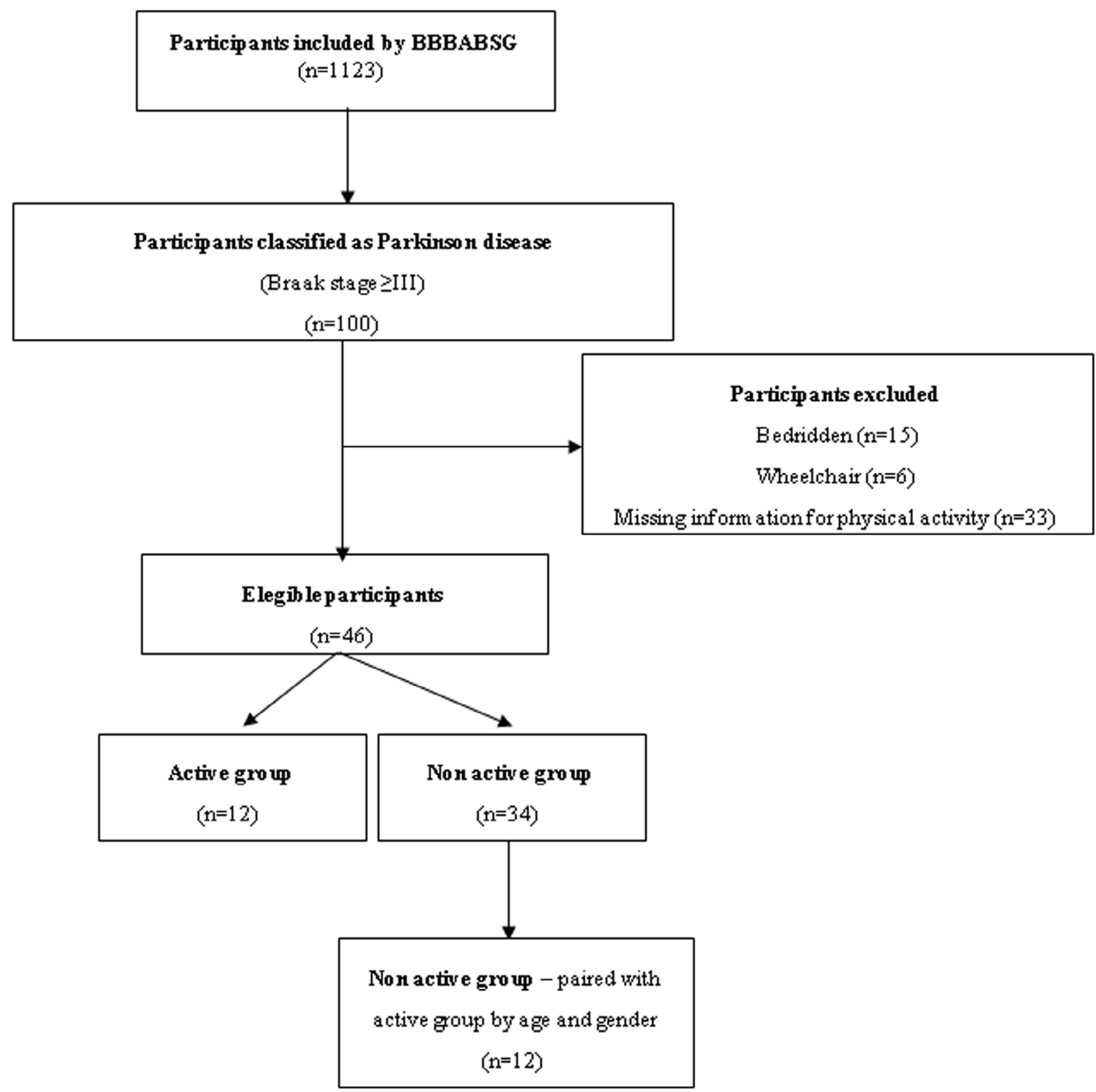

Figure 1. Flowchart of the inclusion process of the study participants. 
Table 2 describes the mean and standard deviation of integrated density for each protein analyzed. TH was more highly expressed in the active group than in the non-active one in the $\mathrm{SN}(\mathrm{p}=0.04)$ (Figures $2 \mathrm{~A}$ and $2 C)$ and in the basal ganglia $(\mathrm{p}=0.04)$ (Figures 2B and 2D). On the other hand, astrocyte was decreased in the substantia nigra of the active group compared to the non-active one $(\mathrm{p}=0.03)$ (Figures $2 \mathrm{E}$ and $2 \mathrm{G})$ and increased in the basal ganglia among the non-active participants compared to the active participants $(\mathrm{p}<0.001)$ (Figures $2 \mathrm{~F}$ and $2 \mathrm{H}$ ).

For MAP2, there were no differences between the groups in the substantia nigra $(\mathrm{p}=0.46)$ (Figures $3 \mathrm{~A}$ and $3 C$ ), while the expression was higher in the nonactive group than in the active group in the basal ganglia $(\mathrm{p}=0.003)$ (Figures $3 \mathrm{~B}$ and $3 \mathrm{D})$. Neurofilaments were more highly expressed in the non-active group than in the active one in the SN ( $\mathrm{p}=0.006)$ (Figures $3 \mathrm{E}$ and $3 \mathrm{G}$ ), while no differences were observed between groups in the basal ganglia $(\mathrm{p}=0.24)$ (Figures $3 \mathrm{~F}$ and $3 \mathrm{H})$.

\section{DISCUSSION}

The present study is the first to correlate protein expression in individuals with proved LBP classified as PD, with an active lifestyle using human brain tissue. The active group, which included participants who walked at least three times a week during the year prior to death, showed higher expression of TH and lower expression of astrocytes in the midbrain and basal ganglia areas. On the other hand, MAP2 and neurofilament expression were higher in non-active subjects. Thus, this study can help explain the effects of physical activity on clinical progression improvement in PD patients.

It is important to reinforce that despite the small sample of subjects, all tissue samples analyzed in our study included only PD subjects with Braak stage $\geq$ III, and with the same Braak AD between groups confirmed by neuropathological classification. In addition, the Braak staging for PD was similar between groups, however the Tanner scale revealed more parkinsonism symptoms in the non-active participants, corroborating previous studies. ${ }^{27}$

Table 1. Characteristics of the sample $(n=24)$.

\begin{tabular}{|c|c|c|c|}
\hline & Non-active $(n=12)$ & Active $(n=12)$ & p-value \\
\hline Age (years), mean $\pm \mathrm{SD}^{*}$ & $80.8 \pm 2.42$ & $81.2 \pm 2.52$ & 0.71 \\
\hline Male, $n(\%) \dagger$ & $7(58.3)$ & $7(58.3)$ & 1.00 \\
\hline Braak PD staging $\geq 111, n(\%)^{\dagger}$ & $12(100)$ & $12(100)$ & 1.00 \\
\hline Clinical Dementia Rating CDR $>0, n(\%)^{\dagger}$ & $8(66.7)$ & $5(41.7)$ & 0.45 \\
\hline Braak AD staging $\geq 1 \mathrm{II}, \mathrm{n}(\%)^{\dagger}$ & $9(75)$ & $9(75)$ & 1.00 \\
\hline Tanner score, mean $\pm \mathrm{SD}^{\star}$ & $3.42 \pm 3.20$ & $0.67 \pm 1.07$ & 0.03 \\
\hline
\end{tabular}

*paired t-test; 'MCNemar test; PD: Parkinson's disease; AD: Alzheimer's disease; SD: standard deviation.

Table 2. Protein expression in the substantia nigra and basal ganglia according to physical activity status $(n=24)$.

\begin{tabular}{|c|c|c|c|c|}
\hline & \multicolumn{2}{|c|}{ Substantia Nigra } & \multicolumn{2}{|c|}{ Basal Ganglia } \\
\hline & Non-active $(n=12)$ & Active $(n=12)$ & Non-active $(n=12)$ & Active $(n=12)$ \\
\hline Tyrosine hydroxylase & \multirow{2}{*}{$2.21 \pm 1.62$} & \multirow{2}{*}{$3.90 \pm 1.63$} & \multirow{2}{*}{$0.51 \pm 0.28$} & \multirow{2}{*}{$1.09 \pm 0.77$} \\
\hline mean $\pm S D\left(10^{7}\right)^{\star}$ & & & & \\
\hline Microtubule-associated protein 2 & \multirow{2}{*}{$1.86 \pm 1.05$} & \multirow{2}{*}{$1.54 \pm 0.81$} & \multirow{2}{*}{$1.57 \pm 0.73$} & \multirow{2}{*}{$0.73 \pm 0.41$} \\
\hline mean $\pm S D\left(10^{7}\right)^{\star}$ & & & & \\
\hline Neurofilaments & \multirow{2}{*}{$1.07 \pm 0.43$} & \multirow{2}{*}{$0.58 \pm 0.24$} & \multirow{2}{*}{$2.53 \pm 1.32$} & \multirow{2}{*}{$3.28 \pm 1.43$} \\
\hline mean $\pm S D\left(10^{7}\right)^{\star}$ & & & & \\
\hline Glial fibrillary acidic protein & \multirow{2}{*}{$2.44 \pm 0.83$} & \multirow{2}{*}{$1.69 \pm 0.70$} & \multirow{2}{*}{$1.99 \pm 0.60$} & \multirow{2}{*}{$1.09 \pm 0.54$} \\
\hline mean $\pm S D(107)^{\star}$ & & & & \\
\hline
\end{tabular}

*paired t-test. Data are expressed as the integrated density mean in an area of $0.58 \mathrm{~mm}^{2}$. 
Physical activity can slow down the aging process, which involves astrocytic, ${ }^{28}$ as well as promotes better motor learning capacity, through increased plasticity in motor-related structures. ${ }^{29}$ Progressive resistance exercise in $\mathrm{PD}$ patients with akinesia and rigidity can improve static posturography, gait, and quality of life. ${ }^{30}$ Comparisons between patients with PD who self-reported regular exercise ( $\geq 2.5$ hours per week) and people who exercise $<2.5$ hours per week revealed positive effects of exercise on health-related quality of life and mobility changes over two years. The benefit of exercise on health-related quality of life was greater in advanced than mild PD. ${ }^{31} \mathrm{~A}$ recent clinical trial with 128 PD patients, followed for 3 years and with half the subjects undergoing exercise protocols, demonstrated that a high-intensity treadmill exercise protocol was
A

B
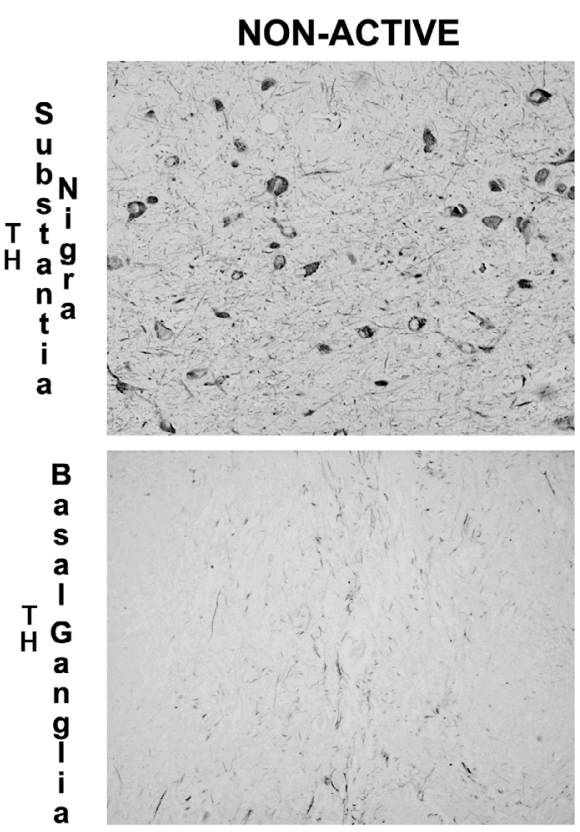

E

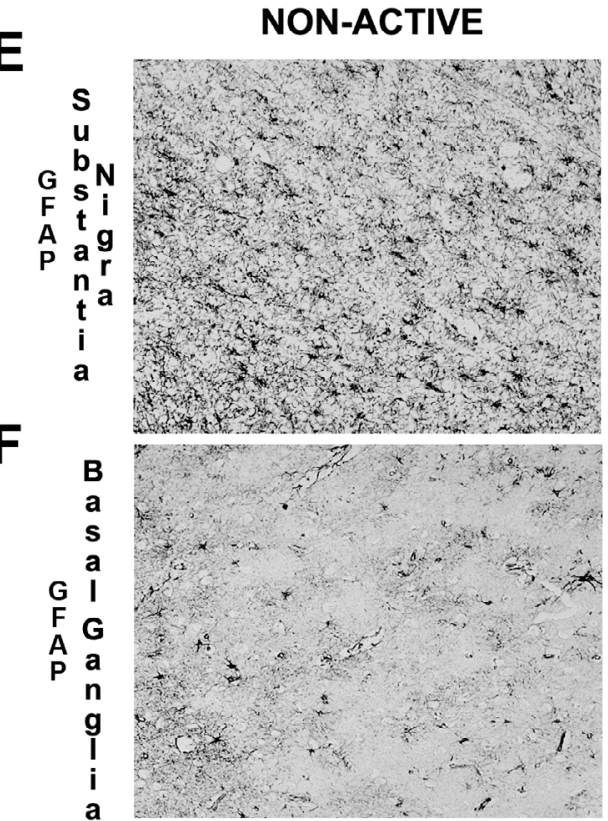

ACTIVE
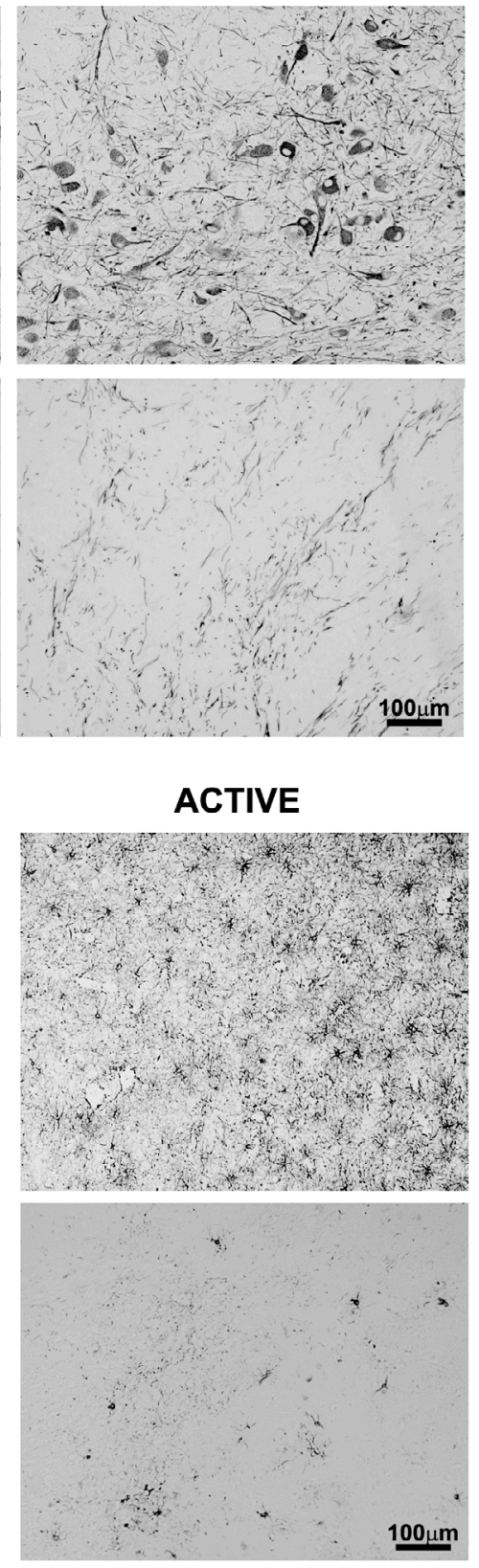

${ }^{*} \mathrm{p}<0.05 ;{ }^{* \star *} \mathrm{p}<0.001$
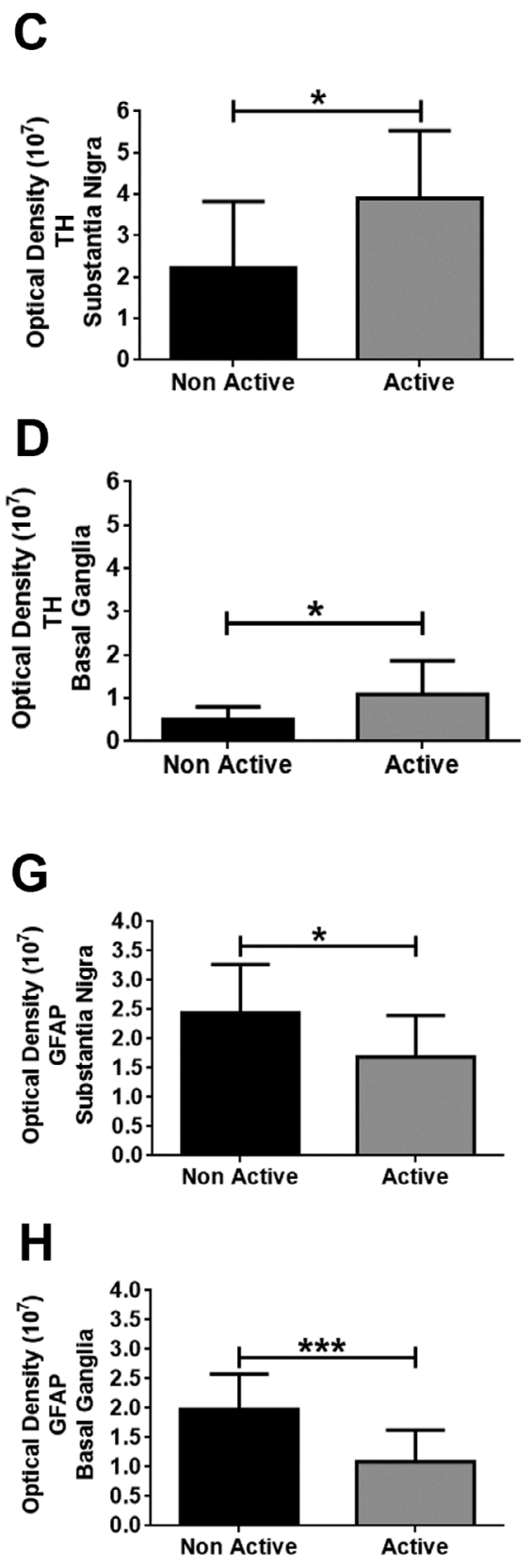

Figure 2. Digital images and graphics for tyrosine hydroxylase in the substantia nigra $(A, C)$ and basal ganglia $(B, D)$; and for glial fibrillary acidic protein in the substantia nigra ( $E$ and $G$ ) and basal ganglia $(F$ and $H)$. 
able to promote improvement in Unified Parkinson's Disease Rating Scale motor scores. ${ }^{32}$

The current findings on $\mathrm{TH}$ expression in human postmortem material corroborate our previous studies with a 6-hydroxydopamine PD-like animal model. In animal models, treadmill exercise 3 times/week for 40 minutes led to the neuroprotection of the dopaminergic system with high TH expression in exercised animals, regardless of the exercise protocol. ${ }^{16,17}$
Despite the ability of different exercise protocols to protect the dopaminergic system and benefit the nervous system, better effects are found when the exercise begins earlier. ${ }^{15}$ In addition to high $\mathrm{TH}$ expression in the postmortem material from active participants, it was possible to observe that astrocytic activation was related to an increase in GFAP expression, which was also found in a previous study. ${ }^{33}$ Astrocyte dysfunction has been described in LBP given the critical role of this
A

B

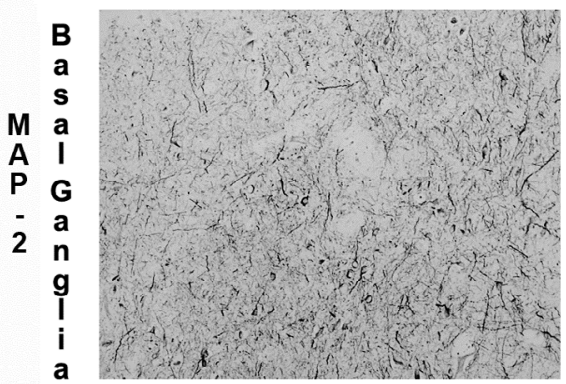

E

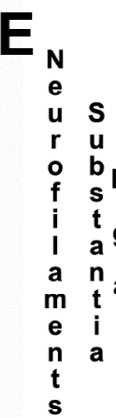

F
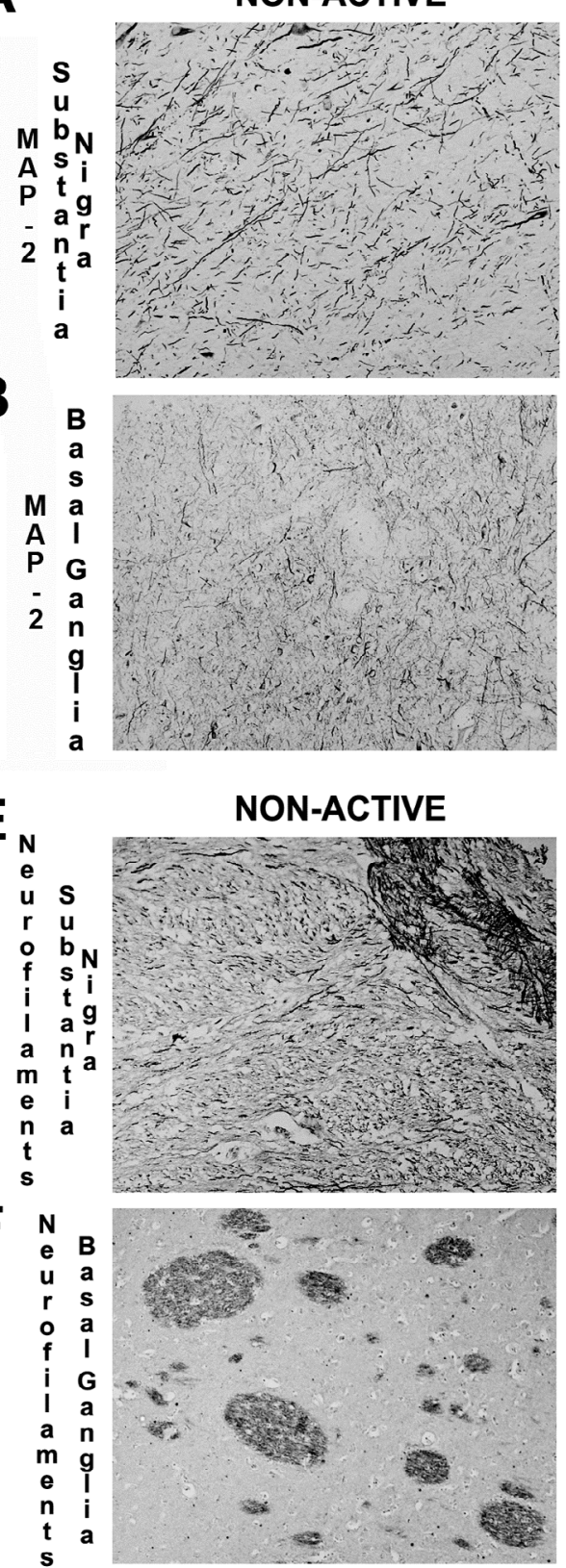
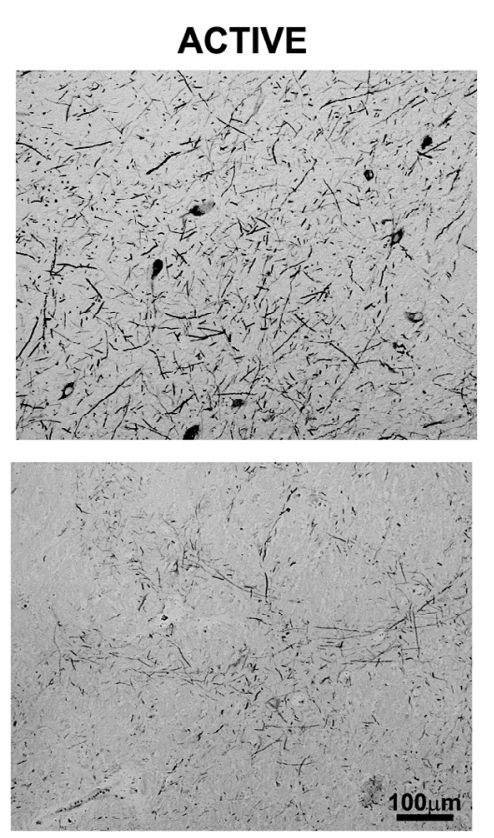

C
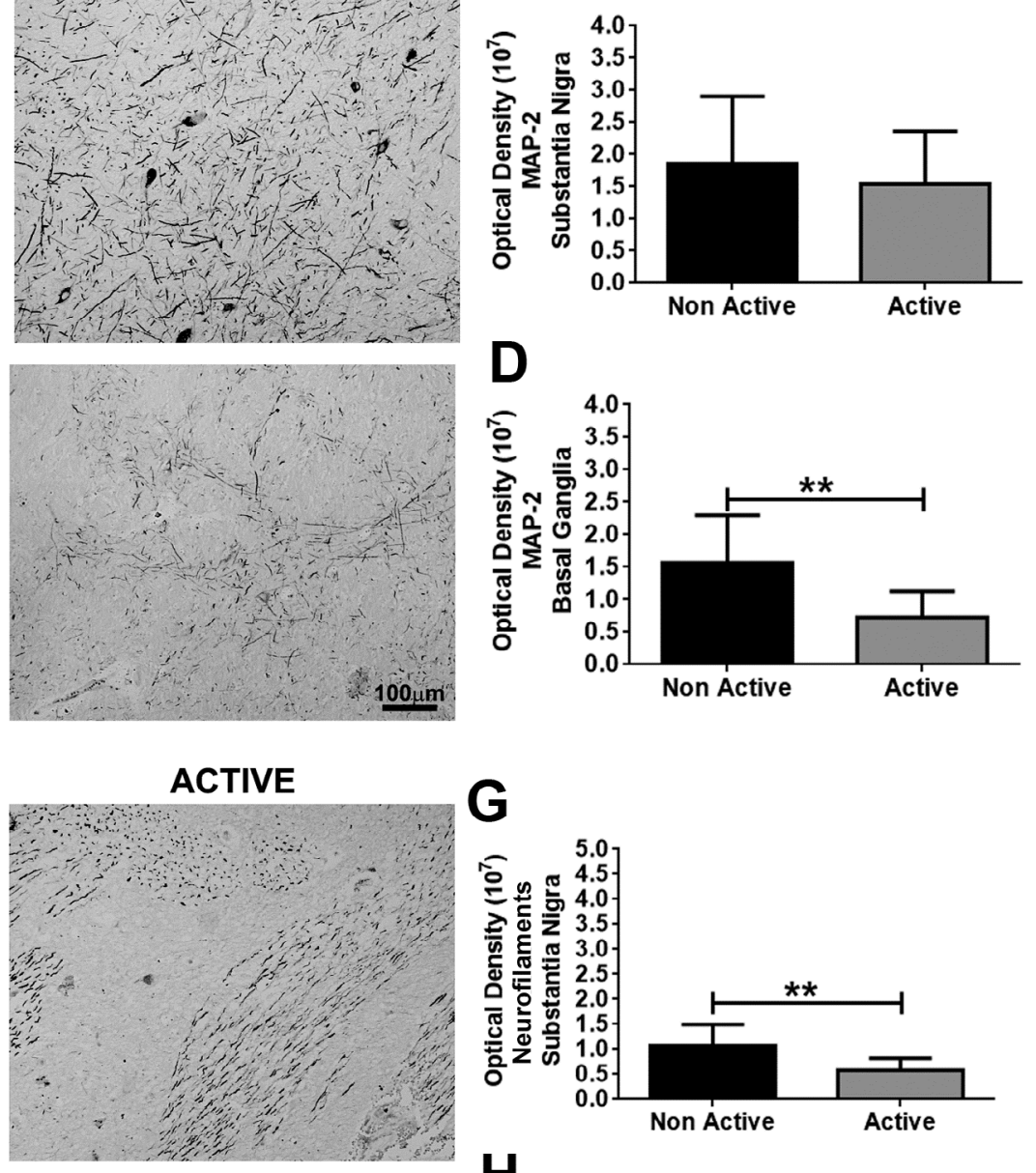

\section{G}
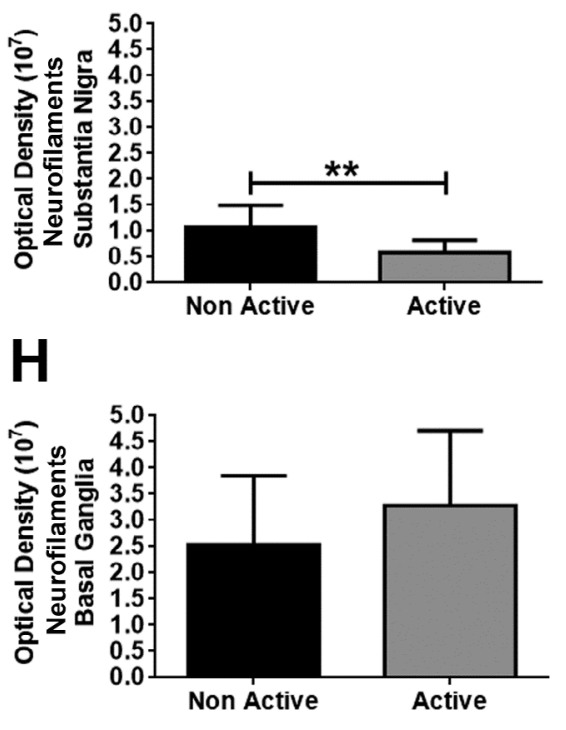

MAP2: microtubule-associated protein 2; ${ }^{\star \star} \mathrm{p}<0.01$

Figure 3. Digital images and graphics for microtubule-associated protein 2 in the substantia nigra (A, C) and basal ganglia (B, D); and for neurofilaments in the substantia nigra $(E, G)$ and basal ganglia $(F, H)$. 
glial subtype in the metabolic and structural support of the nervous system. ${ }^{7}$

Studies suggest that astrocytes play an important role in the pathology and propagation of $\mathrm{PD}$, since they sustain a hazardous environment and further promote dopaminergic neurodegeneration. The pathology of PD is not limited to neurons but extends to astrocytes, since the accumulation of $\alpha$-synuclein is not only found in neurons, but also extends to astrocytes, which are capable of clearing $\alpha$-synuclein deposits from neurons. After taking up $\alpha$-synuclein, astrocytes are proposed to release cytokines including tumor necrosis factor and interleukin-6, thereby causing inflammatory responses, which can promote PD progression. ${ }^{5}$ However, the exact role of these cells on the pathophysiology of PD is still controversial, since they can also be active anti-inflammatory pathways. ${ }^{8}$ Nevertheless, the findings from PD postmortem studies on GFAP expression are inconsistent, since some have revealed GFAP upregulation and typical reactive morphology and others, minimal or mild astrogliosis in patients with $\mathrm{PD} .{ }^{5}$ The finding of decreased GFAP expression in active participants corroborated with studies in PD-like rat models that have described reduced GFAP, dopaminergic neuron protection, and improvements in motor behavior after a treadmill exercise protocol. ${ }^{16}$

In human postmortem material, there is a decrease in axonal transport in subjects in early phases of PD when compared to subjects without dopaminergic degeneration. In contrast, in the symptomatic phase of $\mathrm{PD}$, there is an increase in MAP2 and neurofilaments. ${ }^{34}$ These proteins, in the presence of $\alpha$-synuclein protein, worsen clinical symptoms. ${ }^{10}$ In addition, the present study evidenced reduced expression of these proteins in the active group, which could be related to fewer symptoms of parkinsonism and better TH expression. AD-brain-isolated tau protein was also observed to costain with both endogenous tau and MAP2, suggesting sequestration of these proteins, and $\alpha$-synuclein also binds MAP2 in vitro. The sequestration of other MAPs may play an important role in the ability of the hyperphosphorylated Tau protein to cause microtubules instability and neurodegeneration, suggesting that the non-active group may have worse stability of microtubules in the basal ganglia. ${ }^{11}$

The majority of neurodegenerative disorders are proteinopathies, i.e., they are diseases of protein homeostasis with proteins misfolding and accumulating in aggregates, including PD. ${ }^{13}$ The high expression of neurofilaments in the non-active group when compared to the active one can suggest an increase in protein aggregation and PD progression, evidenced in our study with worsening of TH levels in non-active group. The mechanism by which neurofilaments aggregate is still unknown, but hyper-phosphorylation, which is the overexpression of neurofilaments, is considered one of the main triggers for neurofilaments (NF) aggregation, ${ }^{13}$ including higher levels of neurofilaments in the cerebrospinal fluid. ${ }^{12}$

A major limitation of this study is that there was no information on exercise intensity and duration per session, as well as information on how many years the participant walked for. This information could be relevant because in animal models, the type, duration, and frequency of exercise are associated with plastic responses in the nervous system. ${ }^{35,36}$ In our cross-sectional study, questionnaires were evaluated postmortem, which can cause information bias, though they were also validated for postmortem interview, ${ }^{19}$ and used before by other studies. ${ }^{20,37,38}$ Another limitation is the absence of control cases, future studies should include subjects without neurodegenerative disease neuropathology. Also a limitation is the presence of mixed neuropathology, since $75 \%$ of our sample had a significant number of neurofibrillary tangles. However, it is important to note that the Braak score for $\mathrm{AD}$ was similar between the non-active and active groups.

Despite the fact that our sample contains subjects with cognitive impairment defined as $C D R \geq 0.5$, there was no statistical difference between groups regarding the CDR. In a validation study of the postmortem interview, we found a high accuracy for normal cognition and moderate and advanced dementia; and lower accuracy was found for questionable and mild dementia. ${ }^{19}$ Although the information on cognitive impairment was used to describe the sample, it is important to highlight that the main study variable was LBP based on a neuropathological examination, which is not subject to bias related to postmortem evaluation. In addition, non-active and active groups were paired by age and gender, reducing the confounding chance by these variables.

In conclusion, in participants with similar LBP burden, classified as PD, an active lifestyle may improve dopamine synthesis and structural protein expression in the nigrostriatal system as well as decrease astrocyte activation, which are associated with neuronal death and the worsening of clinical symptoms in neurodegenerative diseases. Our study showed similar results to those found in animal models of PD that could explain the benefits of physical activity in the clinical improvement of PD patients who underwent exercise protocols. Future studies in human brain samples that evaluate the frequency, duration, and intensity of exercise are 
important to better understand the clinical effects of exercise on PD pathophysiology.

\section{ACKNOWLEDGEMENTS}

This study was supported by The São Paulo Research Foundation (FAPESP, Brazil), Coordination for the Improvement of Higher Education Personnel (CAPES, Brazil), Research Center on Applied Neuroscience (NAPNA, Brazil) and The National Council for Scientific and Technological Development (CNPq, Brazil). Thanks are also due to Adilson S. Alves for technical assistance. CCR and KHB were the recipient of a fellowship from FAPESP (2013/25049-2 and 2016/16166-3, respectively).
Authors' contribution. CCR: Conceptualization, Data curation, Formal analysis, Investigation, Methodology, Project administration, Resources, Visualization, and Writing - original draft; CKS: Conceptualization, Formal analysis, Resources, Visualization, and Writing - review; KHB: Formal analysis, Investigation, and Writing - review; LTG: Resources, and Writing review; CAP: Resources, and Writing - review; WJF: Resources, and Writing - review; RELFR: Resources, and Writing - review; RN: Resources, and Writing - review; REPL: Conceptualization, Resources, and Writing - review; Luiz R Britto: Conceptualization, Funding acquisition, Supervision, Resources, and Writing - review.

\section{REFERENCES}

1. Dickson DW, Braak H, Duda JE, Duyckaerts C, Gasser T, Halliday GM, et al. Neuropathological assessment of Parkinson's disease: refining the diagnostic criteria. Lancet Neurol. 2009;8(12):1150-7. https://doi. org/10.1016/S1474-4422(09)70238-8

2. Walker $L$, Stefanis $L$, Attems J. Clinical and neuropathological differences between Parkinson's disease, Parkinson's disease dementia and dementia with Lewy bodies - current issues and future directions. J Neurochem. 2019;150(5):467-74. https://doi.org/10.1111/jnc.14698

3. Toulorge D, Schapira AH, Haij R. Molecular changes in the postmortem parkinsonian brain. J Neurochem. 2016;139 Suppl 1:27-58. https://doi. org/10.1111/jnc. 13696

4. Khan W, Priyadarshini M, Zakai HA, Kamal MA, Alam Q. A brief overview of tyrosine hydroxylase and $\alpha$-synuclein in the Parkinsonian brain. CNS Neurol Disord Drug Targets. 2012;11(4):456-62. https://doi. org/10.2174/187152712800792929

5. Zeng Z, Roussakis AA, Lao-Kaim NP, Piccini P. Astrocytes in Parkinson's disease: from preclinical assays to in vivo imaging and therapeutic probes. Neurobiol Aging. 2020;95:264-270. https://doi.org/10.1016/j.neurobiolaging.2020.07.012

6. Booth HDE, Hirst WD, Wade-Martins R. The role of astrocyte dysfunction in Parkinson's disease pathogenesis. Trends Neurosci. 2017;40(6):358-70. https://doi.org/10.1016/j.tins.2017.04.001

7. Doty KR, Guillot-Sestier MV, Town T. The role of the immune system in neurodegenerative disorders: adaptive or maladaptive? Brain Res. 2015;1617:155-73. https://doi.org/10.1016/j.brainres.2014.09.008

8. Domingues AV, Pereira IM, Vilaça-Faria H, Salgado AJ, Rodrigues AJ, Teixeira FG. Glial cells in Parkinson's disease: protective or deleterious? Cell Mol Life Sci. 2020;77(24):5171-88. https://doi.org/10.1007/s00018020-03584-x

9. Venkatramani A, Panda D. Regulation of neuronal microtubule dynamics by tau: Implications for tauopathies. Int J Biol Macromol. 2019;133:47383. https://doi.org/10.1016/j.jibiomac.2019.04.120

10. D'Andrea MR, llyin S, Plata-Salaman CR. Abnormal patterns of microtubule-associated protein-2 (MAP-2) immunolabeling in neuronal nuclei and Lewy bodies in Parkinson's disease substantia nigra brain tissues. Neurosci Lett. 2001;306(3):137-40. https://doi.org/10.1016/s03043940(01)01811-0

11. Carnwath T, Mohammed R, Tsiang D. The direct and indirect effects of $\alpha$-synuclein on microtubule stability in the pathogenesis of Parkinson's disease. Neuropsychiatr Dis Treat. 2018;14:1685-95. https://doi. org/10.2147/ndt.S166322

12. Yuan A, Rao MV, Veeranna, Nixon RA. Neurofilaments and Neurofilament Proteins in Health and Disease. Cold Spring Harb Perspect Biol. 2017;9(4):a018309. https://doi.org/10.1101/cshperspect.a018309

13. Didonna A, Opal P. The role of neurofilament aggregation in neurodegeneration: lessons from rare inherited neurological disorders. Mol Neurodegener. Mol Neurodegener. 2019;14(1):19. https://doi.org/10.1186/ s13024-019-0318-4

14. Sun F, Norman IJ, While A. E. Physical activity in older people: a systematic review. BMC Public Health. 2013;13:449. https://doi.org/10.1186/14712458-13-449
15. Amara AW, Chahine L, Seedorff N, Caspell-Garcia CJ, Coffey C, Simuni T; Parkinson's Progression Markers Initiative. Self-reported physical activity levels and clinical progression in early Parkinson's disease. Parkinsonism Relat Disord. 2019;61:118-25. https://doi.org/10.1016/j. parkreldis.2018.11.006

16. Real CC, Garcia PC, Britto LR. Treadmill Exercise Prevents Increase of Neuroinflammation Markers Involved in the Dopaminergic Damage of the 6-OHDA Parkinson's Disease Model. J Mol Neurosci. 2017;63(1):36-49. https://doi.org/10.1007/s12031-017-0955-4

17. Real CC, Doorduin J, Kopschina Feltes P, Vállez García D, de Paula Faria $D$, Britto LR, et al. Evaluation of exercise-induced modulation of glial activation and dopaminergic damage in a rat model of Parkinson's disease using [(11)C]PBR28 and [(18)F]FDOPA PET. J Cereb Blood Flow Metab. 2019;39(6):989-1004. https://doi.org/10.1177/0271678X17750351

18. Grinberg LT, Ferretti REL, Farfel JM, Leite R, Pasqualucci CA, Rosemberg $\mathrm{S}$, et al. Brain bank of the Brazilian aging brain study group - a milestone reached and more than 1,600 collected brains. Cell Tissue Bank. 2007:8(2):151-62. https://doi.org/10.1007/s10561-006-9022-z

19. Ferretti RE, Damin AE, Brucki SM, Morillo LS, Perroco TR, Campora F, et al. Post-Mortem diagnosis of dementia by informant interview. Dement Neuropsychol. 2010;4(2):138-44. https://doi.org/10.1590/S198057642010DN40200011

20. Suemoto CK, Ferretti-Rebustini RE, Rodriguez RD, Leite RE, Soterio L, Brucki SM, et al. Neuropathological diagnoses and clinical correlates in older adults in Brazil: A cross-sectional study. PLoS Med. 2017;14(3):e1002267. https://doi.org/10.1371/journal.pmed.1002267

21. Braak $\mathrm{H}$, Braak E. Neuropathological stageing of Alzheimer-related changes. Acta Neuropathol. 1991;82(4):239-59. https://doi.org/10.1007/ BF00308809

22. Mirra SS, Heyman A, McKeel D, Sumi SM, Crain BJ, Brownlee LM, et al. The Consortium to Establish a Registry for Alzheimer's Disease (CERAD). Part II. Standardization of the neuropathologic assessment of Alzheimer's disease. Neurology. 1991;41(4):479-86. https://doi.org/10.1212/ wnl.41.4.479

23. Braak H, Del Tredici K, Rüb U, de Vos RA, Jansen Steur EN, Braak E. Staging of brain pathology related to sporadic Parkinson's disease. Neurobiol Aging. 2003;24(2):197-211. https://doi.org/10.1016/s01974580(02)00065-9

24. Mackenzie IR, Neumann M, Bigio EH, Cairns NJ, Alafuzoff I, Kril J, et al. Nomenclature and nosology for neuropathologic subtypes of frontotemporal lobar degeneration: an update. Acta Neuropathol. 2010;119(1):1-4. https://doi.org/10.1007/s00401-009-0612-2

25. Braak H. Braak E. Cortical and subcortical argyrophilic grains characterize a disease associated with adult onset dementia. Neuropathol Appl Neurobiol 1989;15:13-26. https://doi.org/10.1111/j.1365-2990.1989. tb01146.x

26. Andrade-Moraes $\mathrm{CH}$, Oliveira-Pinto AV, Castro-Fonseca E, da Silva CG, Guimarães DM, Szczupak D, Parente-Bruno DR, et al. Cell number changes in Alzheimer's disease relate to dementia, not to plaques and tangles. Brain. 2013;136(Pt 12):3738-52. https://doi.org/10.1093/brain/ awt273 
27. Obeso JA, Stamelou M, Goetz CG, Poewe W, Lang AE, Weintraub D, et al. Past, present, and future of Parkinson's disease: a special essay on the 200th Anniversary of the Shaking Palsy. Mov Disord. 2017;32(9):1264310. https://doi.org/10.1002/mds.27115

28. Di Benedetto S, Müller L, Wenger E, Düzel S, Pawelec G. Contribution of neuroinflammation and immunity to brain aging and the mitigating effects of physical and cognitive interventions. Neurosci Biobehav Rev. 2017;75:114-28. https://doi.org/10.1016/j.neubiorev.2017.01.044

29. Duchesne C, Gheysen F, Bore A, Albouy G, Nadeau A, Robillard ME, et al. Influence of aerobic exercise training on the neural correlates of motor learning in Parkinson's disease individuals. Neuroimage Clin. 2016;12:55969. https://doi.org/10.1016/j.nicl.2016.09.011

30. Santos L, Fernandez-Rio J, Winge K, Barragán-Pérez B, González-Gómez L, Rodríguez-Pérez $\bigvee$, et al. Effects of progressive resistance exercise in akinetic-rigid Parkinson's disease patients: a randomized controlled trial. Eur J Phys Rehabil Med. 2017;53(5):651-63. https://doi.org/10.23736/S1973-9087.17.04572-5

31. Rafferty MR, Schmidt PN, Luo ST, Li K, Marras C, Davis TL, et al. Regular exercise, quality of life, and mobility in Parkinson's disease: a longitudinal analysis of national Parkinson foundation quality improvement initiative data. J Parkinsons Dis. 2017;7(1):193-202. https://doi.org/10.3233/JPD-160912

32. Schenkman M, Moore CG, Kohrt WM, Hall DA, Delitto A, Comella CL, et al. Effect of high-intensity treadmill exercise on motor symptoms in patients with de novo Parkinson disease: a phase 2 randomized clinical trial. JAMA Neurol. 2018;75(2):219-26. https://doi.org/10.1001/jamaneurol.2017.3517
33. Eddleston M, Mucke L. Molecular profile of reactive astrocytes - implications for their role in neurologic disease. Neuroscience. 1993;54(1):15-36. https://doi.org/10.1016/0306-4522(93)90380-x

34. Chu Y, Morfini GA, Langhamer LB, He Y, Brady ST, Kordower JH. Alterations in axonal transport motor proteins in sporadic and experimental Parkinson's disease. Brain. 2012;135(Pt 7):2058-73. https://doi.org/10.1093/ brain/aws133

35. Arida RM, Scorza FA, Gomes da Silva S, Cysneiros RM, Cavalheiro EA. Exercise paradigms to study brain injury recovery in rodents. Am J Phys Med Rehabil. 2011 Jun;90(6):452-65. https://doi.org/10.1097/ PHM.0b013e3182063a9c

36. Real CC, Garcia PC, Britto LR, Pires RS. Different protocols of treadmill exercise induce distinct neuroplastic effects in rat brain motor areas. Brain Res. 2015;1624:188-198. https://doi.org/10.1016/j.brainres.2015.06.052

37. de Oliveira KC, Nery FG, Ferreti RE, Lima MC, Cappi C, Machado-Lima A, et al. Brazilian psychiatric brain bank: a new contribution tool to network studies. Cell Tissue Bank. 2012;13(2):315-26. https://doi.org/10.1007/ s10561-011-9258-0

38. Grinberg LT, Ferretti RE, Leite REP, Farfel JM, Pacheco SP, Alho AT, et al. Clinicopathological correlates of Alzheimer's disease in a general autopsy series from Brazil. Dement Neuropsychol. 2007;1(4):356-360. https://doi. org/10.1590/S1980-57642008DN10400005 